\title{
Sustainable Organization of Cooperation Activities in a Company
}

\author{
Jakub Soviar, Viliam Lendel, Josef Vodák, and Jana Kundríková \\ University of Žilina, Faculty of Management Science and Informatics \\ Univerzitná 8215/1, 01026 Žilina, Slovak Republic \\ \{jakub.soviar, viliam. lendel, josef.vodak, jana.kundrikova\}@fri. \\ uniza.sk
}

\begin{abstract}
Goal of the article is to use detailed literature analysis and findings of an empirical research, and to propose efficient organization of cooperation activities in a company. The proposed efficient organization enabled authors to describe the process of creating a cooperating company and the individual recommended types of organizational structures. The article thus provides a tool for company managers for managing their cooperation projects and activities. Use of this tool is meant to help minimize occurrence of conflict situations and to support smooth progress of cooperation activities from the organizational perspective. This tool means also a strong sustainable aspect concerning the cooperation's overall stability.
\end{abstract}

Keywords: cooperation management, organization, cooperation project, matrix of organizational structures, sustainable approach.

\section{Introduction}

The topic of managing cooperation activities is currently highly up to date. In present, cooperation as such represents for a company an important tool for increasing its competitiveness. Companies no longer develop their cooperation activities based on "impressions" or "gut feelings", but rather based on knowledge derived from the opinions of their customers, employees and partners. They collect the necessary information, support creation of knowledge, explore market opportunities and make decisions about the need to cooperate. Companies aim to fully utilize their cooperation potential. In order to be successful, it is needed to effectively manage these activities and to dynamically react to the ongoing market development. Here we can use the proposed matrix of cooperation organizational structures, which will ensure efficient organization of the emerging market opportunities using the created cooperation.

The article aims to offer, in an understandable form, a coherent perspective on the management of cooperation activities in a company as well as a methodology of organizing its cooperation projects. Both of these would be based on a comprehensive mapping of theoretical and practical findings in the area of cooperation management as well as the performed research about its utilization in Slovak enterprises. 
The main goal of the article is to produce new insights in the area of cooperation management, with particular focus on its definition within management, and its potential use for managing cooperation projects and activities of a company. Identification of suitable organizational structures may significantly contribute to minimizing occurrence of conflict situations in the process of managing cooperation projects and company activities.

We use several methods to perform our research:

- method of document analysis: for analyzing current as well as historical data about the topic;

- questionnaire survey method and a method of semi-structured interview: for gathering data in an empirical research;

- method of observation: used during visits of selected companies;

- method of quantitative evaluation: for processing the data - statistical methods and tools were applied;

- method of comparison: for comparing data gathered by empirical research and data from the analysis of secondary information sources.

The performed research focused on medium and large enterprises active in the Slovak Republic. The actual respondents were company managers on the mid to top management level within the managerial hierarchy of companies. In total, 273 respondents took part in the research focused on diagnostics of the level of use of cooperation management. Research included companies active in multiple sectors of the Slovak economy. Included companies were categorized by the Statistical Office of the Slovak Republic as medium or large enterprises. The actual respondents were company managers on the mid to top management level within the managerial hierarchy of companies. Size of the sample was 345 respondents, with the required 95 $\%$ interval of reliability and the maximum allowable error of 5\%. Since 273 respondents actually took part in the research, the maximum allowable error reached $5.72 \%$. Data was gathered exclusively via personal interview. Partially results of this research were already published in several papers, e.g. Lendel, 2015 [20]; Vodak, Soviar, Lendel, 2013 [45] and Vodak, Soviar, Lendel, 2015 [46]. We consider this paper as continuation of above mentioned works.

\section{Current State of Dealing with the Issue}

Cooperation is one of the key tools for achieving strategic competitiveness of companies. It is a complex system whose elements are stakeholders striving to achieve certain benefits which would be individually hardly achieved ([16]; [36]). The benefits of cooperation are less likely to emerge in a short time, they show up after a certain lapse of time, so from a long-term perspective it is more profitable to choose cooperation rather than a selfish strategy [26].

Cooperation needs to be properly managed in order to be successful. However, there is still an ongoing scientific discussion regarding the term cooperation management, its definition and the scope of use. Several definitions of cooperation management can be found in the scientific literature, such as following ones. It is a philosophy of management that can be applied irrespective of ownership structure [4]. 
Cooperation management offers effective management of cooperative processes between independent organizations with the aim of continuously improving interorganizational activities and providing flexibility for companies which are facing challenges of today, so that opportunities for cooperative development don't remain unused [3]. However, these definitions of cooperation management typically address only a subset of the whole task of cooperation management. We built this chapter based on our previous published works, mainly [20], [45] and [46]. High variability in interpretation of the term "cooperation management" can be supported by the following examples:

- it is a way of managing and developing collaboration in a competitive environment [19],

- it represents a term for integrated management of company networks [31],

- it is a cooperative decision making process within heterogeneous preferences [38], [44],

- it provides conditions for creating a system of cooperation based on effective use of resources and technologies [49].

The most important characteristics of cooperation management are following [44]:

- It is a complex decision making process and the decisions are made on all managerial levels.

- Primary goal of cooperation management is to satisfy the needs of the members of cooperation.

- All activities need to occur according to the agreed principles of management and cooperation.

- Suitable balance needs to be established between the efforts for commercial success and maintaining goals of the cooperating parties.

- Management focused on reaching a goal via effective use of resources.

Based on the performed detailed analysis, as described above, we can define a more precise definition of this term ([21]; [37]; [47]; [48]): Cooperation management is effective and efficient management of relationships in a cooperation between separate and relatively independent organizations or individuals, with the goal of improving their competitiveness.

Building of relationships based on cooperation and having the following attributes ([2]; [7]; [9]; [13]; [14]; [21]; [22]; [31]; [42]): cooperation and partnership; seriousness; non-disturbance of mutual competitive relationships; focusing particularly on long-term time horizons - long-term cooperation; continuous learning and knowledge transfer; effective and efficient combination of resources - the ability to integrate external resources through net-working.

To build cooperation management in a company is a real challenge that company managers need to deal with. Among a number of factors influencing the process of establishing cooperation management in a company belong following ones:

- The role of innovation: effective cooperation management processes have significant impact considering creating of successful innovations (product, market, services, processes, etc.) ([11]; [18]; [24]; [32]; [34]).

- Mutual trust - trust between the partner organizations: trust is mainly based on previous positive experience and it is also strongly connected with reference power of an organization ([10]; [47]; [48]). 
- Information background (as a cooperation processes support) and knowledge creation: effective management of cooperation processes is strongly dependent on ensuring quality information within the company and to enable its sharing for the decision making needs of the managers ([1]; [6]; [23]).

- Impact of wider - regional environment: a sum of companies in a region, which could be used as an integral part of cooperation management activities; already existing cooperation networks (alliances, clusters...); state of the regional economy, etc. ([17]; [25]; [27]; [30]; [40]).

- Organizational factors: all necessary changes in the organizational structure to support cooperation; new dynamic organization structures (e.g. clusters) ([15]; [27]; [28]; [35]; [39]).

- Geographical proximity of the partners: it is not a necessity.

- Sharing a common purpose, values and objectives; knowledge in the area; and reaching a consensus [33].

Assuming that the abovementioned identified factors are taken care of within a company, then its cooperation management will bring expected results, such as better product quality, shorter delivery times and higher customer satisfaction [41]. This will contribute to the overall competitiveness of the company.

\section{Situation in Slovak Enterprises - Results of Empirical Research}

We conducted our research between September 2012 and February 2013 (further information about this research could be found in our previous published papers [20], [45] and [46]). Our main goal was to gather and interpret information about the level of using cooperations in the environment of Slovak enterprises. In order to reach that goal, our research had to identify the key aspects of efficient management and functioning of cooperations, related issues, degree of satisfaction of companies within cooperation and the opportunities for improvement of already functioning cooperations. All gathered data provided complete picture about readiness of Slovak enterprises to use (implement) cooperation management. In total, 273 managers of small, medium and large enterprises took part in the research, from companies active in Slovak republic. Data from the respondents was gathered via personal interviews. Table 1 provides overview of the main results for the individual researched areas. 
Table 1. Level of use of cooperation management in Slovak enterprises.

\begin{tabular}{|c|c|}
\hline Researched area & Main results \\
\hline $\begin{array}{l}\text { Area of the most } \\
\text { developed cooperation }\end{array}$ & $\begin{array}{l}\text { - Supplier relationships }(68.13 \%) \\
\text { - Purchasing relationships }(52.38 \%) \\
\text { - Technical cooperation }(44.32 \%) \\
\text { - Education }(35.16 \%) \\
\text { - Advertising and promotion }(24.18 \%)\end{array}$ \\
\hline $\begin{array}{l}\text { The most preferred areas } \\
\text { of interest for a more } \\
\text { intense cooperation in the } \\
\text { near future }\end{array}$ & $\begin{array}{l}\text { - Purchasing of products and services }(59.23 \%) \\
\text { - Supplying of products and services }(57.69 \%) \\
\text { - Technical cooperation }(43.08 \%) \\
\text { - Technical consulting }(25.38 \%) \\
\text { - Advertising, promotion }(23.08 \%)\end{array}$ \\
\hline $\begin{array}{l}\text { Main issues arising when } \\
\text { cooperating with other } \\
\text { organizations }\end{array}$ & $\begin{array}{l}\text { - Insufficient adherence to the agreed contractual } \\
\text { terms }(58.39 \%) \\
\text { - Financially demanding }(35.04 \%) \\
\text { - Distortion of information }(34.41 \%) \\
\text { - Low effectiveness of cooperation }(29.56 \%) \\
\text { - Unwillingness to provide internal information by } \\
\text { a cooperating company, i.e. concerns about } \\
\text { providing internal information to a company } \\
(28.83 \%) \text {. }\end{array}$ \\
\hline $\begin{array}{l}\text { Main benefits resulting } \\
\text { from cooperation }\end{array}$ & $\begin{array}{l}\text { - Good mutual relations }(26.62 \%) \\
\text { - Improved profit }(20.78 \%) \\
\text { - Reduced costs }(20.13 \%) \\
\text { - Improved competitiveness }(15.58 \%)\end{array}$ \\
\hline $\begin{array}{l}\text { Areas for improvement in } \\
\text { cooperation }\end{array}$ & $\begin{array}{l}\text { - Improved communication }(31.78 \%) \\
\text { - Adherence to contractual terms }(23.08 \%) \\
\text { - Improved effectiveness of cooperation }(22.14 \%)\end{array}$ \\
\hline
\end{tabular}

It could be considered positive that almost half of the respondents $(47.62 \%)$ plans in the near future (within one year) to establish a more intense cooperation with a company or an organization. When selecting partners for cooperation, companies make decisions based on the following factors: costs (8.12), insolvency (8.03), market position (7.25), profitability (7.18) and certificates (7.05). In contrast, the lowest importance was assigned to the factors such as the legal form (4.16) and company seat. 


\section{Proposal for Effective Organization of Cooperation Activities of a Company}

During the process of managing cooperation processes in a company, company strategy is revised and modified so that it reflects the plans of top management regarding management of cooperation activities. However, such a change can end up influencing the roles of multiple employees. Depending on the character and number of realized cooperation projects, it is necessary to revise the currently used company organizational structure and to adapt it to the current situation.

Given great variability of cooperation projects, it is possible to use multiple types of organizational structures for their organization. The general rule is that the organizational structure adapts to the cooperation project (content, complexity, extent, time needs) and not vice versa.

Organization remains of key importance in the process of managing cooperation activities, especially in today's turbulent environment. Cooperation management aims to ensure competitiveness of the company in such environment. However, for this to happen it is needed that the company is capable to dynamically react to the arising changes.

Here is room for using dynamic cooperation organization structures that offer immediate reaction and consequent change in configuration of employees and processes, as necessary. Therefore, such organization structures enable cooperation with partners in the area of research and development, marketing etc., as well as work on multiple project at the same time. Dynamic cooperation organization structures (champions, purpose teams, project teams, project centers...) are characterized by the following properties:

- ability to rapidly react to changes,

- de-centralized management,

- use of the creative approach,

- flexibility in content and activities of the groups and individuals,

- acceptance of higher degree of uncertainty and risk in management,

- direct evaluation and testing of new ideas,

- focus on results,

- adequate number of management levels,

- administratively undemanding methods of management,

- high added value,

- informal team work,

- lower number of organizational elements and connections,

- lower requirements on the management system.

For the purpose of fulfilling the organizational needs related to managing cooperation activities, a matrix of cooperation organizational structures was created (Fig. 1). Cooperation organizational structures are located in the matrix based on two main parameters - number of realized cooperation projects and how demanding/complex are the cooperation projects. 


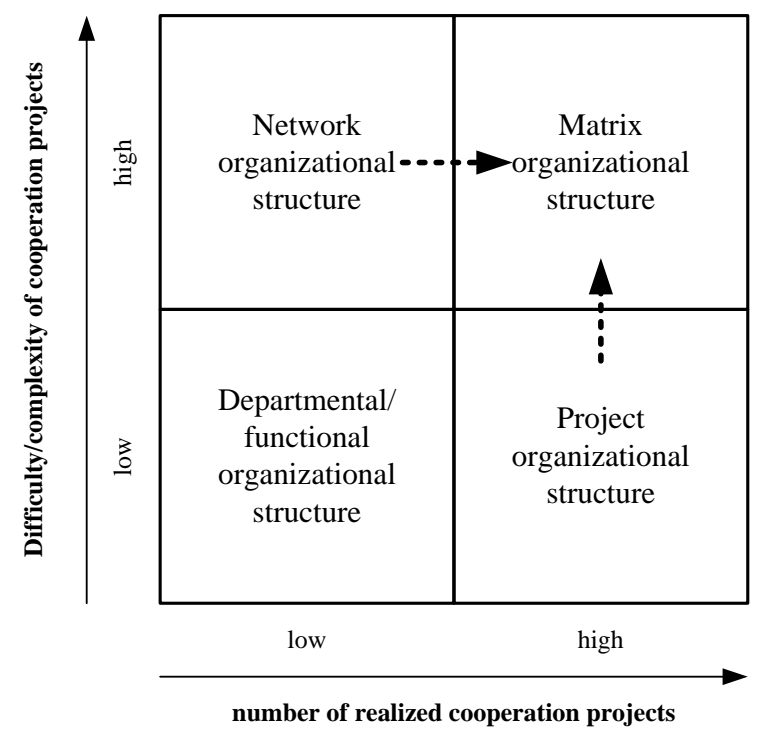

Fig. 1. Matrix of cooperation organizational structures.

In the first quadrant we can find the functional organizational structure. This is a classic organizational structure, suitable for situations with low number of realized cooperation projects with relatively low complexity. Company employees are managed by their superior within a department to which they are assigned. Their work position does not change, i.e. they stay on their linear positions. Communication in this organizational structure takes a form of coordination work meetings of cooperation teams. The role of line managers is to ensure the process of planning, realization and control of cooperation activities.

In the second quadrant we can find the project organization structure. It is used mainly in situations when company realizes multiple projects with relatively low complexity. If necessary and if existentially important for the company, it is possible to use this organizational structure to deal with demanding and complex cooperation projects (represented by the arrow in the Fig. 1). In this organizational structure, members of project teams are freed from their permanent work position.

In the third quadrant we can find network organizational structure. It enables to deal with complex and demanding cooperation projects and if necessary also multiple projects at the same time (represented by the arrow in the Fig. 1). This organizational structure is characterized by high degree of flexibility and dynamics. Cooperation projects are managed in required time and quality, while a relationship is being established with the main organization.

In the last quadrant we can find matrix organizational structure. Due to its structure, it enables dealing with multiple cooperation projects with high degree of complexity. It also enables efficient use of company resources. Employees are managed by a project leader, while they also remain on their functional positions. 


\section{Discussion}

Organization, whether commercial or not, is a social group. Its goal is to fulfill the set goals. Cooperating organization have certain categories in common. Most often these are common goals that can be reached more effectively via cooperation [45]. Organizations assume culture of the society from which they stem and at the same time they create their own (organizational or company culture). Success represents an important aspect - this is represented in a way by company survival, market success, profit etc. If organization is not in the long-term successful in fulfilling its goals or it is not competitive, one of the solutions is to connect with other organization or organizations.

Figure 2 represents basic steps necessary for creating cooperating organization. Organizations exist in a state of mutual competition. In case a certain problem turns out to be significant enough, it may represent a potential stimulus for establishing mutual cooperation. Mutual discussion and agreement leads to cooperation. Organizations exist in a dynamic environment that creates further changes that in turn create need for another discussion (planning and decision making). This may result in a decision to continue the cooperation, to modify it or to terminate it and to return to mutual competition.

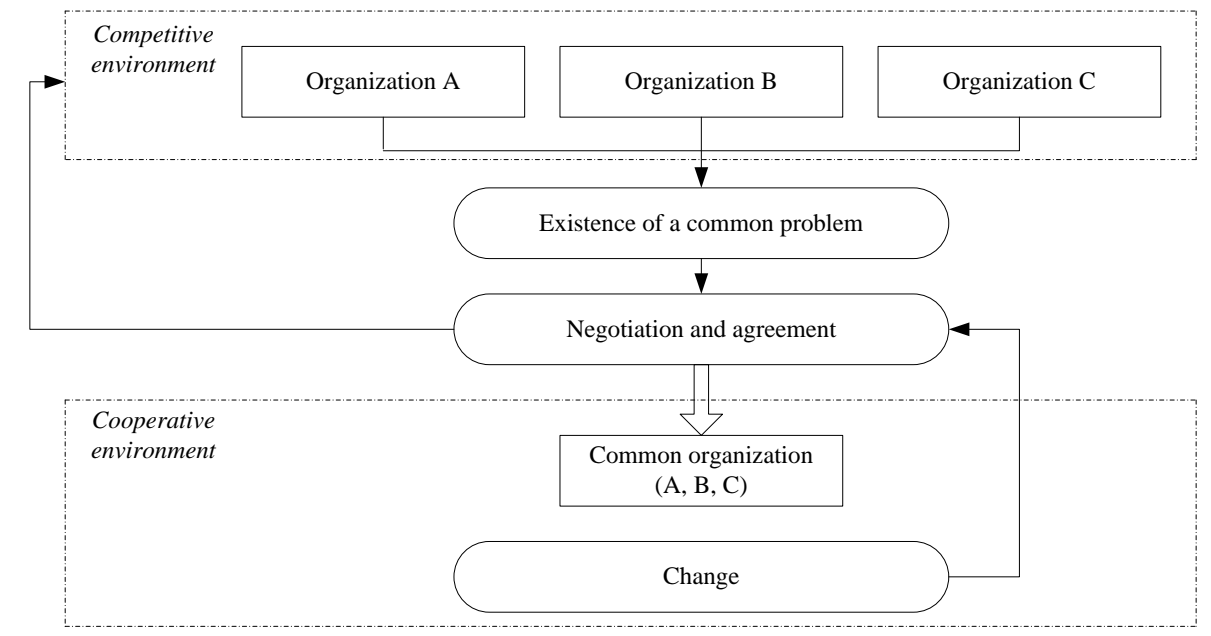

Fig. 2. Process of creating cooperation organization.

The described aspects form dynamic cooperation organizational structures, that are created, modified and terminated, depending on current goals and tasks. One organization could participate in multiple dynamic organizational structures. It could also be the case that only a part of organization participates. This arrangement enables individual structures and employees to work on tasks from multiple projects, depending on the current needs. The cooperation organization itself takes on standard organizational structures.

Frequently we encounter matrix organizational structure, which suitably addresses the needs created by the environment dynamics. This type of organizational structure 
is also partially defined by the management literature: "Virtual organization or organization with virtual organizational structure is a special type of organization. It differs significantly from the hierarchical organizations. It is a temporary connection of companies, based on information technologies. Its purpose is to rapidly and efficiently use available entrepreneurial opportunities. Subjects connected within the virtual organization are not connected via ownership, and do not form formal organizational structures. Rather, they are independent and each of them contribute to taking advantages of the opportunity by its specific skill and obtains that what could not be obtained in being isolated." [43]

Although the sustainability concept is mainly oriented on ecological or environmental issues it is widely used also in socio-economic context ([5]; [8]; [12]). E.g. Delai and Takahashi refer to "consensus around three main dimensions of sustainability - economic, social, and environmental" [5]. They define the social and economic dimensions as following: "The economic dimension assesses short and long term value generation by a company and its relationship with shareholders. It is related with the long-term sustainability of an organization." "In the organization point-of-view, the social dimension of sustainability concerns impacts on the social systems within which it operates or its stakeholders" [5]. Effective cooperation management between independent organizations have also strong sustainable aspect:

- it is oriented on long-lasting solutions;

- it is mutual beneficial for all participants (common sources or value creation...);

- cooperation based organization structures (e.g. clusters) have high probability for creation of positive externalities and have significant potential for innovations ([28]; [29]).

\section{Conclusion}

New cooperating organization creates new quality of culture, which will be based on the cultures of the cooperating subjects. Cultural similarity plays a certain role here, as cooperation strategy is often used by small and medium organizations that are regionally concentrated. On the other hand, e.g. joint-venture is often established by transnational corporations. Culture also determines values that are attractive for the subjects to such a degree that they decide to cooperate (competitiveness, effectiveness). Inequality will manifest particularly in the organizational structure of the new organization. It can also manifest depending on the division of decision making influence between the cooperating parties. Conflict should be here seen more broadly, as it is mainly a negotiation. Cooperating subjects may have different opinions about the future direction of the cooperating organization. If agreement or compromise is not found, change will take place. Change is here understood as a modification of the organization (new goals, change of partners etc.) or as its termination, in case it loses its relevance for the cooperating subjects (or at least for the critical number of involved subjects).

Proposed matrix of cooperating organizational structures is meant to serve as a tool for managers of cooperating companies for managing their cooperating projects and activities. Its use is meant to help minimize occurrence of conflict situations and 
to support smooth progress of cooperation activities from the organizational perspective.

Acknowledgments. This paper is an output of the science projects - Slovak Republic scientific grants VEGA 1/0617/16; VEGA 1/0621/14 and APVV-15-0511.

\section{References}

1. BIGGIERO, L. (2006) Industrial and knowledge relocation strategies under the challenges of globalization and digitalization: the move of small and medium enterprises among territorial systems. Entrepreneurship and Regional Development 18(6): 443-471.

2. CHESBROUGH, H. W., VANHAVERBEKE, W. and WES, J. (2006). Open innovation: Researching a new paradigm. (Oxford: Oxford University Press).

3. DAVIS, P. (1999) Managing the cooperative difference: A Survey of the application of modern management practices in the cooperative context. (Geneva: International Labour Office).

4. DAVIS, P. and DONALDSON, J. (1998) Co-operative Management: A Philosophy for Business, Cheltenham. (Cheltenham: New Harmony Press).

5. DELAI, I. and TAKAHASHI, S. (2011) Sustainability measurement system: A reference model proposal. Social Responsibility Journal 7(3): 438-471.

6. DÍAZ PIRAQUIVE, F. N.; MEDINA GARCIA, V. H.; CRESPO, R. G. and LIBERONA, D. (2014) Knowledge Management, Innovation and Efficiency of Service Enterprises Through ICTs Appropriation and Usage. In: UDEN, L.; OSHEE, D. F., TING, I. and LIBERONA, D [ed.], Knowledge Management in Organizations, Lecture Notes in Business Information Processing Volume 185, p. 300-311 (Springer International Publishing), ch. 29.

7. DOZ, Y. L. (1996) The evolution of cooperation in strategic alliances: Initial conditions or learning process? Strategic Management Journal 17(S1): 55-83.

8. DYLLICK, T. and HOCKERTS, K. (2002) Beyond the Business Case for Corporate Sustainability. Business strategy and the Environment 11(2): 130-141.

9. EISENHARDT, K. M.; FURR, N. R. and BINGHAM, C. B. (2010) CROSSROADSMicrofoundations of performance: Balancing efficiency and flexibility in dynamic environments. Organization Science 21(6): 1263-1273.

10.FAWCETT, S. E.; JONES S. L. and FAWCETT A. M. (2012) Supply chain trust: The catalyst for collaborative innovation. Business Horizons 55(2): 163-178.

11.FELZENSZTEIN, CH.; GIMMON, E. and AQUEVEQUE, C. (2012) Cluster or unclustered industries? Where inter-firm marketing cooperation matters. Journal of Business \& Industrial Marketing 27(5): 392-402.

12.GALPIN, T. and WHITTINGTON, J. L. (2012) Sustainability leadership: from strategy to results. Journal of Business Strategy 33(4): 40-48.

13.GUMILAR, V.; ZARNIĆ, R. and SELIH, J. (2011) Increasing Competitiveness of the Construction Sector by Adopting Innovative Clustering. Inzinerine Ekonomika-Engineering Economics 22(1): 41-49.

14.GURRIERI, A. R. (2013) Networking entrepreneurs. Journal of Socio-Economics 47(C): 193-204.

15.JASSAWALLA, A. R. and SASHITTAL, H. C. (1998) An examination of collaboration in high-technology new product development processes. Journal of Product Innovation Management 15(3): 237-254.

16.KETELS, CH. and SÖLVELL, Ö. (2007) Innovation Clusters in the 10 new member states of the European Union. (Luxembourg: European Union's publisher). 
17.KOWALSKI, A. M. and MARCINKOWSKI, A. (2014) Clusters versus Cluster Initiatives, with Focus on the ICT Sector in Poland. European Planning Studies 22(1): 20-45.

18.KULTTI, K. (2011) Sellers like Clusters. Journal of Theoretical Economics 11(1).

19.LAFLEUR, M. (2009) A Model for Cooperative Challenges [online]. Cooperative Grocer Network 116 [ref. 17 November 2014]. Available at: http://www.cooperativegrocer.coop/articles/2009-01-21/model-cooperative-challenges

20.LENDEL, V. (2015) Application of Cooperative Management in Enterprises: Management Approach, Problems and Recommendations. In SROKA, W. and HITTMÁR, S. [ed.] Management of Network Organizations - Theoretical Problems and the Dilemmas in Practice (Springer International Publishing), ch. 5.

21.LYDEKA, Z. and ADOMAVIČIUS, B. (2007) Cooperation among the Competitors in International Cargo Transportation Sector: Key Factors to Success. Inzinerine EkonomikaEngineering Economics 51(1): 80-90.

22.MALAKAUSKAITE, A. and NAVICKAS, V. (2010) Relation between the Level of Clusterization and Tourism Sector Competitiveness. Inzinerine Ekonomika-Engineering Economics 21(1): 60-67.

23.MONCZKA, R. M.; PETERSEN, K. J.; HANDFIELD, R. B. and RAGATZ, G. L. (1998) Success factors in strategic supplier alliances: The buying company perspective. Decision Sciences 29(3): 553-577.

24.MUSTAK, M. (2014) Service innovation in networks: a systematic review and implications for business-to-business service innovation research. Journal of Business \& Industrial Marketing 29(2): 151-163.

25.NEMCOVA, E. (2004) The function of clusters in the development of region. Ekonomicky casopis 52(6): 739-754.

26.PERRU, O. (2006) Cooperation strategies, signals and symbiosis. Comptes Rendus Biologies 329(12): 928-937.

27.PERRY, M. (2007) Business environments and cluster attractiveness to managers. Entrepreneurship and Regional Development 19(1): 1-24.

28.PORTER, E. M. (1998) Clusters and the New Economics of Competition [online]. Harward Business Review Nov-Dec: 25-26. [ref. 26 September 2016]. Available at: https://hbr.org/1998/11/clusters-and-the-new-economics-of-competition

29.PORTER, M. E. (1998) On Competition. (Boston: Harvard Business School).

30.RAMANAUSKIENÉ, J. and RAMANAUSKAS, J. (2006) Economic Management Aspects of Cooperatives. Economics of Engineering Decisions 49(4): 15-21.

31.RAY, P. K. (2002) Cooperative Management of Enterprise Networks. (New York: Kluwer Academic Publishers).

32.RITALA, P., SAINIO, L. M. (2014) Coopetition for radical innovation: technology, market and business-model perspectives. Technology Analysis \& Strategic Management 26(2): 155-169.

33.ROBSON, M. and KANT, S. (2006) The development of government agency and stakeholder cooperation: A comparative study of two Local Citizens Committees' (LCC) participation in forest management in Ontario, Canada. Forest Policy and Economics 9(8): 1113-1133.

34.SAHUT, J. M. and PERIS-ORTIZ, M. (2014) Small Business, innovation, and entrepreneurship. Small Business Economics 42(4): 663-668.

35.SCHMOLTZI, C. and WALLENBURG, C. M. (2012) Operational Governance in Horizontal Cooperations of Logistics Service Providers: Performance Effects and the Moderating Role of Cooperation Complexity. Journal of Supply Chain Management 48(2): 53-74.

36.SOLVELL, O.; LINDQVIST, G. and KETELS, CH. (2003) The Cluster Initiative Greenbook. (Stockholm: Bromma tryck AB). 
37.SOVIAR, J. (2012) From Cooperation to Management - Cooperative management (in Slovak). [Habilitation thesis]. University of Zilina, Faculty of Management Science and Informatics.

38.STAATZ, J. M. (1983) The Cooperative as a Coalition: A Game-Theoretic Approach. American Journal of Agricultural Economics 65(5): 1084-1089.

39.STABER, U. (2010) Imitation without Interaction: How Firms Identify with Clusters. Organization Studies 31(2): 153-174.

40.SZEKELY, V. (2008) Regional industrial clusters and problems (not only) with their identification. Ekonomicky casopis 56(3): 223-238.

41.VALENZUELA, J. L. D. and VILLACORTA, F. S. (1999) The relationship between the companies and their suppliers. Journal of Business Ethics 22(3): 273-280.

42.VARMUS, M. (2009) Comparison of Selected Concepts Strategies. In Hittmár, Š. and Sroka, W. [ed.], Theory of Management 1 Žilina: University of Zilina), 169-173.

43.VEBER, J. et al. (2006) Management. Foundations, Prosperity, Globalization (in Slovak). (Praha: Management Press).

44.VEERAKUMARAN, G. (2006) COCM 511 - Management of Cooperatives and Legal Systems, Faculty of Dryland Agriculture and Natural Resources, Mekelle University.

45.VODÁK, J.; SOVIAR, J. and LENDEL, V. (2013) Identification of the main problems in using cooperative management in Slovak enterprises and the proposal of convenient recommendations. Communications - Scientific letters of the University of Žilina 15(4): 6367.

46.VODÁK, J.; SOVIAR, J. and LENDEL, V. (2015) Proposal for Effective Planning of Cooperation Activities in a Company. In Proceedings of Electronic Government and the Information Systems Perspective, 4th International Conference, EGOVIS 2015, Valencia, Spain, September 1-3, Vol. 9265, (Springer International Publishing), 351-363.

47.WECK, M. and IVANOVA, M. (2013) The importance of cultural adaptation for the trust development within business relationships. Journal of Business \& Industrial Marketing 28(3): 210-220.

48.WICKS, A. C.; BERMAN, S. L. and JONES, T. M. (1999) The structure of optimal trust: Moral and strategic implications. Academy of Management Review 24(1): 99-116.

49.ZHANG, W. (2011) Cooperation System Constructing and Model of its Operation Mechanism. In Proceedings of the International Conference on Business Management and Electronic Information (BMEI), Vol. 3, 784-787. 